\title{
CFRP ile Güçlendirilmiş Eğilme Yükü Etkisindeki Betonarme Kirişlerin Sonlu Elemanlar Yöntemi ile Analizi
}

\author{
${ }^{1}$ Wael Aldhabir, ${ }^{* 2}$ Ali Sarbıyık ve ${ }^{3}$ Emine Aydın \\ ${ }^{1}$ Sakarya Üniversitesi, Mühendislik Fakültesi, İnşaat Mühendisliği Bölümü, Türkiye \\ ${ }^{* 2}$ Sakarya Uygulamalı Bilimler Üniversitesi, Teknoloji Fakültesi, İnşaat Mühendisliği Bölümü, Türkiye \\ ${ }^{3}$ Sakarya Uygulamalı Bilimler Üniversitesi, Teknoloji Fakültesi, İnşaat Mühendisliği Bölümü, Türkiye
}

\section{ÖZET}

$\mathrm{Bu}$ çalışmada, eğilme yüküne karşı Karbon Fiber Takviyeli Polimer (CFRP) kompozitler ile güçlendirilmiş betonarme kirişlerin davranışı Abaqus sonlu elemanlar programı ile modellenmiştir. Düşük dayanımlı beton, yetersiz eğilme ve kesme donatısı kullanılarak üretilen dikdörtgen kesitli betonarme kirişler, tekyönlü karbon kumaşlar enine ve boyuna doğrultularda yönlendirilerek U şeklinde güçlendirilmiştir. Dört nokta eğilme deneyi ile test edilen kirişlerin eğilme davranışları tespit edilerek Sonlu Elemanlar Metoduyla (SEM) ile doğrulanmıştır. SEM programında istenen parametreler, deneysel çalışmalardan, literatürden, modellemede yaygın olarak kullanılan bazı temel formüllerden ve ürün kataloglarından elde edilmiştir. Gerekli parametreler SEM paket programına girilerek betonarme kiriş modeli kurulmuştur. Betonarme kirişin davranışı doğrulanarak CFRP ile güçlendirilmiş kirişler modellenmiştir. SEM'de CFRP kompozitler kabuk eleman olarak kirişin alt ve yan yüzeylerine tanımlanmıştır. Çözüm ağı boyutu ve geometrik şekli, genişleme açısı gibi model parametreleri, betonarme kirişin davranışını önemli ölçüde etkilediği görülmüştür. Elde edilen sonuçlara göre betonarme kiriş için en uygun parametreler tespit edilmiştir. SEM sonuçları deneysel çalışmadan elde edilen yük-sehim grafikleri ile karşılaştırılarak oluşturulan model doğrulanmıştır.

Anahtar Kelimeler: betonarme kiriş, güçlendirme, sonlu elemanlar modeli, CFRP.

\section{Finite Element Analysis of Reinforced Concrete Beams Strengthened by Cfrp under Flexural Loading}

\begin{abstract}
In this study, the behavior of reinforced concrete beams strengthened with Carbon Fiber Reinforced Polymer (CFRP) composites is modeled by abaqus finite element program under Flexural load. Rectangular cross section reinforced concrete beams produced by using low strength concrete, insufficient bending and shear reinforcement are strengthened in $U$ shape by guiding unidirectional carbon fabrics in transverse and longitudinal directions. The Flexural behavior of the beams tested by the four-point bending test was determined and verified by the Finite Element Method (FEM).The parameters required in the FEM program were obtained from experimental studies, literature, some basic formulas commonly used in modeling and product catalogues. The required parameters are entered into the FEM package program and the reinforced concrete beam model is established. The behavior of reinforced concrete beams is confirmed and modeled by CFRP reinforced beams. CFRP composites in FEM are defined as shell elements on the sub-surface and lateral surfaces of the beam. Model parameters, such as mesh size and geometric shape, dilation angle, have been observed to significantly affect the behavior of reinforced concrete beams. According to the results, the most appropriate parameters for reinforced concrete beams were determined. The FEM results were compared with the load-displacement behaviors obtained from the experimental study and the model was verified.
\end{abstract}

Keywords: Reinforced concrete beam, strengthened, finite element model, CFRP

\section{Giriş}

Türkiye'de meydana gelen depremler, mevcut betonarme yapıların önemli bir bölümünün güçlendirilmesi gerektiğini ortaya koymaktadır. Depremler sonrasında betonarme binaların

*Corresponding author: Adres:. Sakarya Uygulamalı Bilimler Üniversitesi, Teknoloji Fakültesi, İnşaat Mühendisliği Bölümü 54187 Sakarya TÜRKIYE E-mail adres: alisaribiyik@sakarya.edu.tr 
çoğunda betonların basınç dayanımlarının oldukça düşük olması, donatı düzensizliği ve yetersizliği vb. nedenler ile betonarme yapılar hasar görmekte veya yıkılmaktadır[1]-[7]. Betonarme kirişlerin onarım ve güçlendirilmesinde çeşitli yöntemler kullanılmaktadır. Kullanılan yöntemlerin başında kirişlerin betonarme elemanlar ile mantolanması gelmektedir. Ancak bu yöntemin zor, zahmetli ve aşırı maliyetli olduğu bilinmektedir. Yapı ağırlığını artırmayan, kolay ve hızlı uygulanabilen, elemanların taşıma kapasitelerini artıran, güçlendirme sırasında yapının kullanımına imkân tanıyan Elyaf Takviyeli Polimer (FRP) kompozitler bu tür problemleri azaltarak betonarme kirişlerin güçlendirilmesinde kullanımı giderek yaygınlaşmaktadır. FRP kompozitler ile güçlendirilmiş kirişler üzerine yapılan deneysel çalışmalar ile kirişlerin taşıma kapasiteleri ve güçlendirme şekilleri araştırılmaktadır[8]-[12]. Sonlu Elemanlar Metodu (SEM) programlarıyla betonarme kirişlerin modellenmesi üzerine birçok çalışma yapılmıştır[13]-[17]. Deneysel çalışmalar zaman ve maliyete neden olduğundan yapılan çalışma sınırlı kalabilmektedir. Deneysel çalışmanın bir sonlu elemanlar yardımı ile hassas bir şekilde modellenmesi ve parametrik çalışmalar ile deneye gerek kalmadan deney verileri üretilebilmesi birçok açıdan avantaj sağlamaktadır. Sonlu Elemanlar Metodu(SEM) günümüzde karmaşık mühendislik problemlerinin hassas olarak çözülmesinde kullanılan ve fayda/maliyet/zaman vb. açsından çok avantajlı olan sayısal analiz metodudur. Modellemeyle yapı elemanlarındaki sorun oluşturabilecek kısımlar detaylı bir şekilde analiz edilebilmektedir ve yapı elemanının davranışını daha iyi anlamak mümkündür.

Bu çalışmada, mevcut betonarme yapılardaki düşük dayanımlı kirişler Karbon Elyaf Takviyeli Polimer (CFRP) kompozitler ile eğilme ve kesme kuvvetine karşı güçlendirilmiş ve sonlu elemanlar paket programı ile doğrulanmıştır. Elde edilen deneysel ve model sonuçları karşılaştırmalı olarak analiz edilmiştir.

\section{Malzeme ve Yöntem}

\subsection{Malzemeler}

Betonarme kirişlerde ortalama $17 \mathrm{MPa}$ basınç dayanımına sahip beton kullanılmıştır. Betonların güçlendirilmesinde tekyönlü karbon elyaf kumaş kullanılmıştır. Karbon elyaf kumaşın dokuma kalınlığı: 0,166 mm, çekme dayanımı: $3900 \mathrm{MPa}$, çekme elastisite modülü: $230000 \mathrm{MPa}$, kopma uzaması: \%1,5; karbon elyaf kumaşın beton yüzeylerine yapıştırılmasında kullanılan epoksi reçinenin çekme dayanımı: $30 \mathrm{MPa}$, çekme elastisite modülü: $4500 \mathrm{MPa}$, kopma uzaması: \%0,9 olarak ürün kataloğundan alınmıştır. Betonarme kirişlerde kullanılan $\phi 8$ 'lik etriye donatısının ortalama akma dayanımı ve çekme dayanımı sırasıyla 368, $525 \mathrm{MPa}$, $\phi 10$ 'luk boyuna donatının ortalama akma dayanımı ve çekme dayanımı sırasıyla 480, 600 MPa'dır.[18].

\subsection{Betonarme kirişler}

Betonarme kirişler 150x250 mm kesitinde ve $2000 \mathrm{~mm}$ uzunluğunda üretilmiştir. Kirişlerin alt ve üst kesitinde $2 \phi 10$ boyuna donatı ve kiriş boyunca $\phi 8 / 150$ etriye bulunmaktadır. Kirişler, U şeklinde, farklı katmanlarda, enine ve boyuna doğrultularda, CFRP kompozitler ile güçlendirilmiştir(Şekil 1). Çalışmada kullanılan kirişlerin bilgileri Tablo 1'de sunulmuştur. Kirişler dört nokta eğilme deneyinde sabit hızlı yükleme ile test edilmiştir[12]. Numune yük ve sehim grafikleri oluşturulduktan sonra SEM ile doğrulama çalışmaları yapılmıştır. 


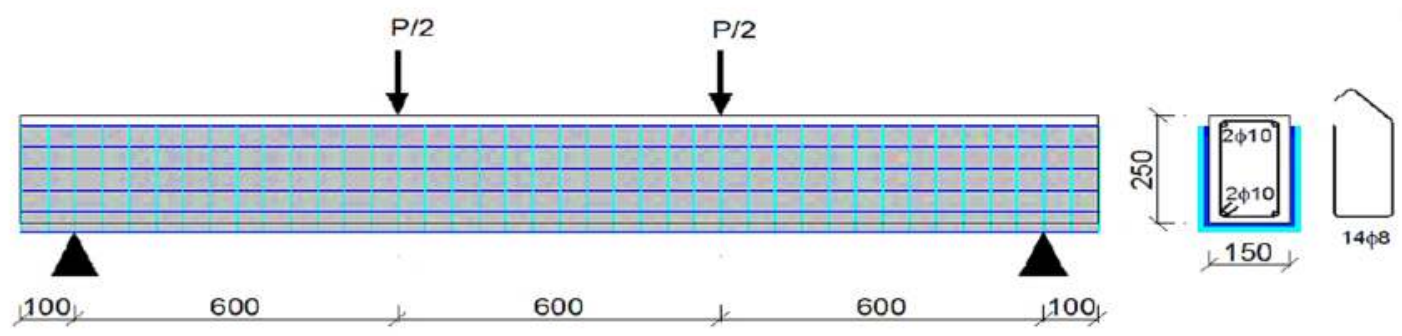

a) Kiriş yükleme durumu

b) Kiriş kesiti

Şekil 1. Betonarme kiriş yükleme durumu (a) ve geometrik özellikleri(b)

Tablo 1. Kiriş numune kodlama ve açıklamaları

\begin{tabular}{|c|c|c|c|}
\hline Kiriş Kodları & Kiriş șekilleri & Kiriş özellikleri & Adet \\
\hline \multirow[t]{2}{*}{ Kontrol } & & \multirow[t]{2}{*}{ Kontrol kirişi } & \multirow[t]{2}{*}{3} \\
\hline & $\mathbf{\Delta}$ & & \\
\hline C11 & $\mathbf{A}$ & $\begin{array}{l}\text { CFRP ile } 1 \text { kat boyuna, } \\
1 \text { kat } 90^{\circ} \text { enine sarglli }\end{array}$ & 3 \\
\hline \multirow{3}{*}{ C22 } & 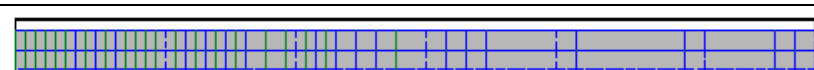 & \multirow{3}{*}{$\begin{array}{l}\text { CFRP ile } 2 \text { kat boyuna, } \\
2 \text { kat } 90^{\circ} \text { enine sargill }\end{array}$} & \multirow{3}{*}{2} \\
\hline & & & \\
\hline & $\mathbf{A}$ & & \\
\hline \multirow[t]{2}{*}{ C21-1 } & 11 & \multirow{2}{*}{$\begin{array}{l}\text { CFRP ile } 2 \text { kat boyuna, } \\
1 \text { kat } 90^{\circ} \text { enine, } 1 \text { kat } \\
45^{\circ} \text { enine sargili }\end{array}$} & \multirow[t]{2}{*}{2} \\
\hline & $\boldsymbol{A}$ & & \\
\hline
\end{tabular}

\subsection{Sonlu elemanlar model çalışmaları}

Sonlu elemanlar yöntemiyle başarılı bir çözüm yapmak öncelikle malzeme modellerinin gerçeğe yakın şekilde tanımlanmasıyla mümkün olmaktadır. Sonlu Elemanlar Metotları, analitik olarak çözümü mümkün olmayan veya karmaşık olan mühendislik problemlerinin çözülmesinde kullanılan sayısal bir yöntemdir. Bu tür bilgisayar programlarından biri olan Abaqus doğrusal ve doğrusal olmayan problemlerin çözümünde yaygın olarak kullanılmaktadır. Betonarme kiriş ve CFRP ile güçlendirilmiş kirişlerin sonlu elemanlar ile modellemesinde deneyde uygulanan sınır şartları dikkate alınarak kiriş modeli üç boyutlu olarak kurulmuştur(Şekil 2, Şekil 3). Programda yükleme deneyde olduğu gibi kiriş üst yüzeyine yapısal tekli yükler (structural distributing) olarak, mesnetler bir taraf sabit diğer taraf hareketli olacak şekilde tanımlanmıştır. CFRP kompozit kiriş̧ alt ve yan yüzeylerine kabuk (Shell) olarak tanımlanmıştır. Analiz türü statik riks olarak tanımlanmıştır. Analiz sonrası yükler mesnetlerden, sehim ise kiriş orta noktasından okunmuştur. 
A $\breve{g}$ boyutu ve geometrik şekli, genişleme açısı gibi model parametreleri üzerinde değişiklikler yaparak model doğrulanmaya çalışılmıştır.

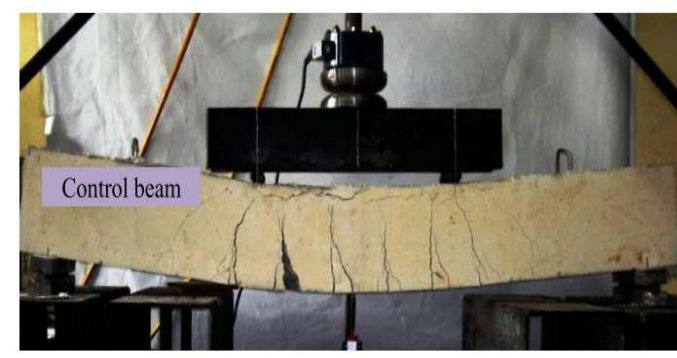

Şekil 2. Betonarme kiriş eğilme testi

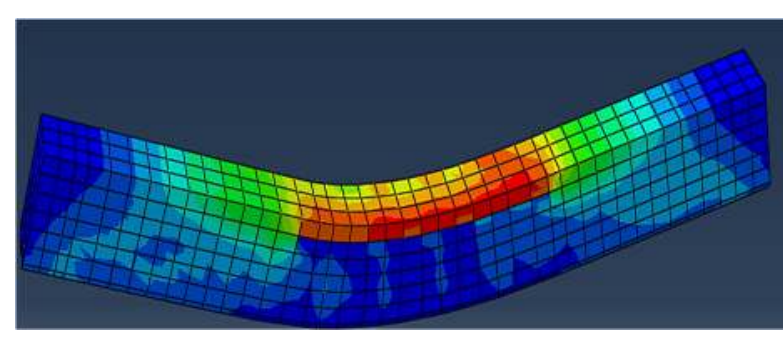

Şekil 3. SEM betonarme kiriş modeli

\subsubsection{Malzeme modeli}

Beton Hasar Plastisite (BHP) yöntemi, beton için sürekli plastisiteye dayalı bir hasar modelidir. BHP yönteme göre çekme çatlaması ve basınç kırılması olmak üzere betonda temel iki önemli yenilme mekanizması vardır. Hasarın oluşumu ve elastik rijitlikte değişimi tanımlamak için iki birim şekil değiştirme değişkeni ( $\varepsilon_{\mathrm{t}}^{\sim \mathrm{pl}}$ ve $\varepsilon_{\mathrm{c}}^{\sim \mathrm{pl}}$ ) sırasıyla çekme ve basma eşdeğer plastik gerilmeler olarak adlandırılır. Betonun mekanik davranışları hakkındaki ana varsayımlar tartışılmaktadır. ABAQUS/Standart User Manual'den alınan BHP, betonun tek eksenli çekme ve basınç gerilmeleri altında gerilme-şekil değiştirme davranışı Şekil 4a,-4b'deki gibi ifade edilmektedir.

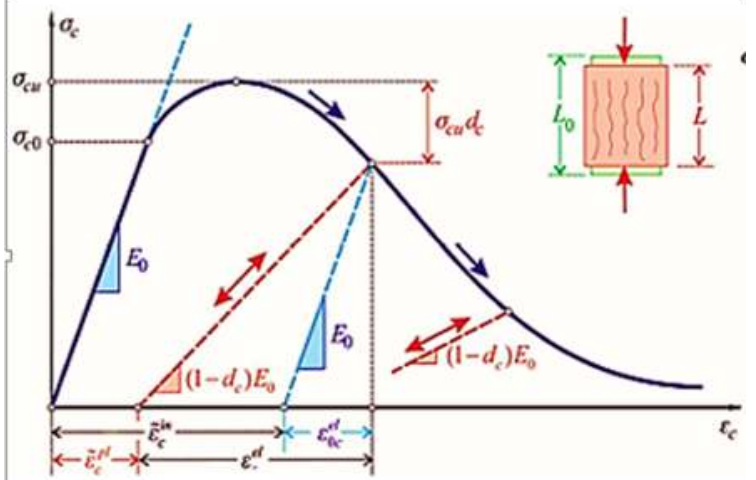

a) Eksenel basınç altında beton davranışı

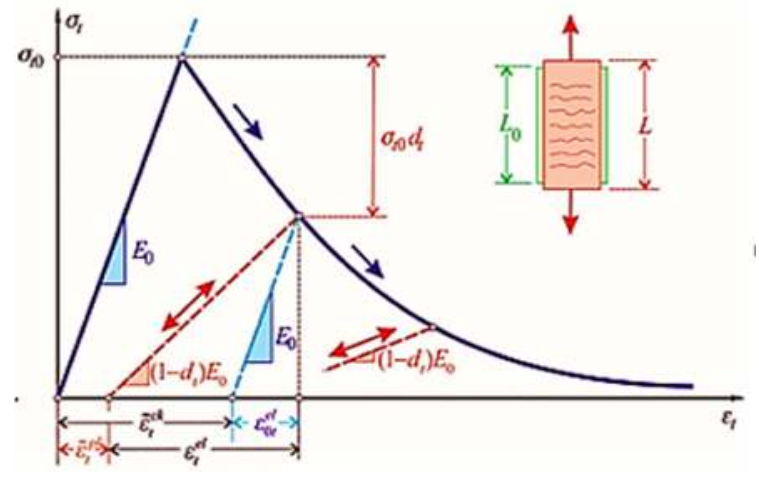

b) Eksenel çekme altında beton davranışı

Şekil 4. Eksenel çekme (a) ve basınç (b) altında beton davranışı

Tek eksenli basınç kuvveti altında ise gerilmeler $6_{\mathrm{c} 0}$ değerine kadar doğrusal elastik kabul edilir. Çekme gerilmesinde ise beton davranışı $6_{\mathrm{t} 0}$ değerine kadar doğrusal bir ilişki izler. Maksimum çekme gerilmesine ulaşılmasıyla betonda çekme çatlağı oluşur. Elastik rijitliğin bozulması, sıcaklığın ve alan değişkenlerinin işlevleri olduğu varsayılan iki hasar değişkeniyle $\left(d_{t}\right.$ ve $\left.d_{c}\right)$ karakterize edilmektedir:

$$
\begin{aligned}
& \mathrm{d}_{\mathrm{t}}=\mathrm{d}_{\mathrm{t}}\left(\varepsilon_{\mathrm{t}}^{\sim \mathrm{pl}}, \theta, \mathrm{f}_{\mathrm{i}}\right) ; 0 \leq \mathrm{d}_{\mathrm{t}} \leq 1, \\
& \mathrm{~d}_{\mathrm{c}}=\mathrm{d}_{\mathrm{c}}\left(\varepsilon_{\mathrm{c}}^{\sim \mathrm{pl}}, \theta, \mathrm{f}_{\mathrm{i}}\right) ; 0 \leq \mathrm{d}_{\mathrm{c}} \leq 1 .
\end{aligned}
$$


Grafiklerde $\mathrm{E}_{0}$ malzeme hasarsız elastisite modülünü göstermekte ve $\varepsilon_{\mathrm{c}}^{\sim \mathrm{pl}}, \varepsilon_{\mathrm{t}}^{\sim \mathrm{pl}}, \varepsilon_{\mathrm{c}}^{\sim \text { in }}, \varepsilon_{\mathrm{t}}^{\sim \text { in }}$ sırasıyla; eksenel basınç plastik şekil değiştirmesini, eksenel çekme plastik şekil değiştirmesini ve elastik olmayan basınç ve çekme şekil değiştirmelerini göstermektedir. Gerilme $\left(\sigma_{t}, \sigma_{\mathrm{c}}\right)$-şekil değiştirmeler $\left(\varepsilon_{\mathrm{t}}, \varepsilon_{\mathrm{c}}\right)$ arasındaki bağıntı aşağıdaki formüller ile ifade edilmektedir:

$$
\begin{aligned}
& \sigma_{\mathrm{t}}=\left(1-\mathrm{d}_{\mathrm{t}}\right) \mathrm{E}_{0}\left(\varepsilon_{\mathrm{t}}-\varepsilon_{\mathrm{t}}^{\sim \mathrm{pl}}\right), \\
& \sigma_{\mathrm{c}}=\left(1-\mathrm{d}_{\mathrm{c}}\right) \mathrm{E}_{0}\left(\varepsilon_{\mathrm{c}}-\varepsilon_{\mathrm{c}}^{\sim \mathrm{pl}}\right),
\end{aligned}
$$

"Etkin" olan çekme ve basınç kohezyonu (cohesion) gerilmelerini $\left(\sigma_{\mathrm{t}}^{-}, \sigma_{\mathrm{c}}^{-}\right)$şu şekilde tanımlanmektedir:

$$
\begin{aligned}
& \sigma_{\mathrm{t}}^{-}=\frac{\sigma_{\mathrm{t}}}{\left(1-\mathrm{d}_{\mathrm{t}}\right)}=\mathrm{E}_{0}\left(\varepsilon_{\mathrm{t}}-\varepsilon_{\mathrm{t}}^{\sim \mathrm{pl}}\right), \\
& \sigma_{\mathrm{c}}^{-}=\frac{\sigma_{\mathrm{c}}}{\left(1-\mathrm{d}_{\mathrm{c}}\right)}=\mathrm{E}_{0}\left(\varepsilon_{\mathrm{c}}-\varepsilon_{\mathrm{c}}^{\sim \mathrm{pl}}\right),
\end{aligned}
$$

Çekme rijitliği ve tek eksenel basınç altında doğrusal olmayan birim şekil değiştirmeler $\operatorname{plastik}\left(\varepsilon_{\mathrm{c}}^{\sim \mathrm{pl}}, \varepsilon_{\mathrm{t}}^{\sim \mathrm{pl}}\right)$ birim şekil değiştirmelere aşağıdaki formülle tanımlanır.

$$
\begin{aligned}
& \varepsilon_{\mathrm{c}}^{\sim \mathrm{pl}}=\varepsilon_{\mathrm{c}}^{\sim \mathrm{in}}-\frac{\mathrm{d}_{\mathrm{c}}}{\left(1-\mathrm{d}_{\mathrm{c}}\right)} \frac{\sigma_{\mathrm{c}}}{\mathrm{E}_{0}}, \\
& \varepsilon_{\mathrm{t}}^{\sim \mathrm{pl}}=\varepsilon_{\mathrm{t}}^{\sim \mathrm{ck}}-\frac{\mathrm{d}_{\mathrm{t}}}{\left(1-\mathrm{d}_{\mathrm{t}}\right)} \frac{\sigma_{\mathrm{t}}}{\mathrm{E}_{0}},
\end{aligned}
$$

Modelde kullanılan betonun basınç dayanımı (17,13 MPa), şekil değiştirme(0,0025) değerleri deney sonuçlarından, Elastisite modülü (19450 MPa) ise Amerikan standardından elde edilerek SEM'e girilmiştir[18]. BHP modeli yukarıda belirtilen denklemler referans alınarak oluşturulmuştur. BHP yönteminde dilasyon Açısı, betonda plastik hacimsel değişmeleri kontrol eden parametredir ve nümerik SEM analizlerde dilasyon açısı yakın değerler için uygunluk araştırmasıyla $50 \mathrm{~mm}$ olarak belirlenmiştir. Nümerik SEM analizlerde beton için tipik değer olarak verilen eksantriktik parametresi: 0,1, ( $\sigma$ bo/ $\sigma c o: 1,16$, Kc: 0,667 kabul edilmiştir. Betonarme kirişlerde doğrusal olmayan malzeme davranışın modellenmesinde yaygın olarak kabul gören Mander[19], Kent ve Park[20] ve Hognestad[21] modeli denenmiştir. Betonarme kirişlerde kullanılan betonun basınç ve çekme hasar davranışı SEM'de oluşturularak Şekil 4'de, donatılara ait hasar davranışı Şekil 5'da örnek olarak sunulmuştur. Mander modeli deneysel çalışmaya daha yakın sonuçlar vermiştir. Çelik donatılar üzerinde yapılan deney sonuçlarından elde edilen verilerle Çelik özellikleri elasto-plastik olarak modellenmiştir(Şekil 6).

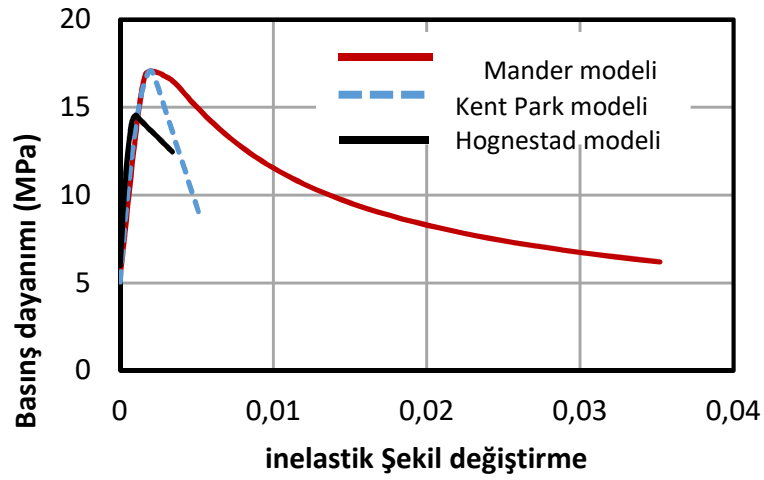

a) Beton basınç hasar davranışı

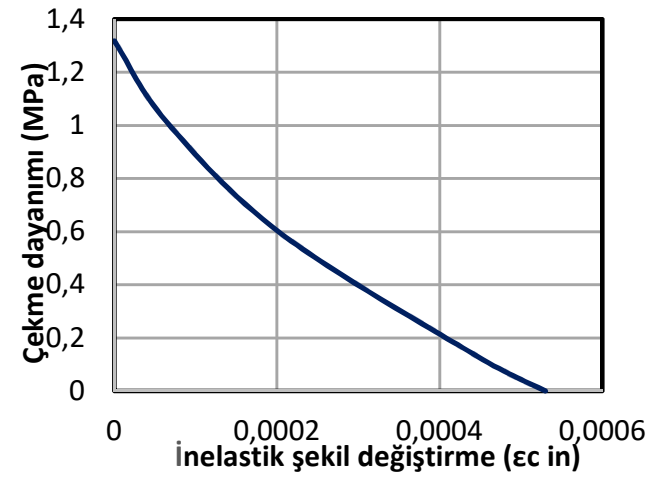

b) Beton çekme hasar davranışı

Şekil 5. Kiriş betonu basınç(a) ve çekme(b) hasar davranışı 


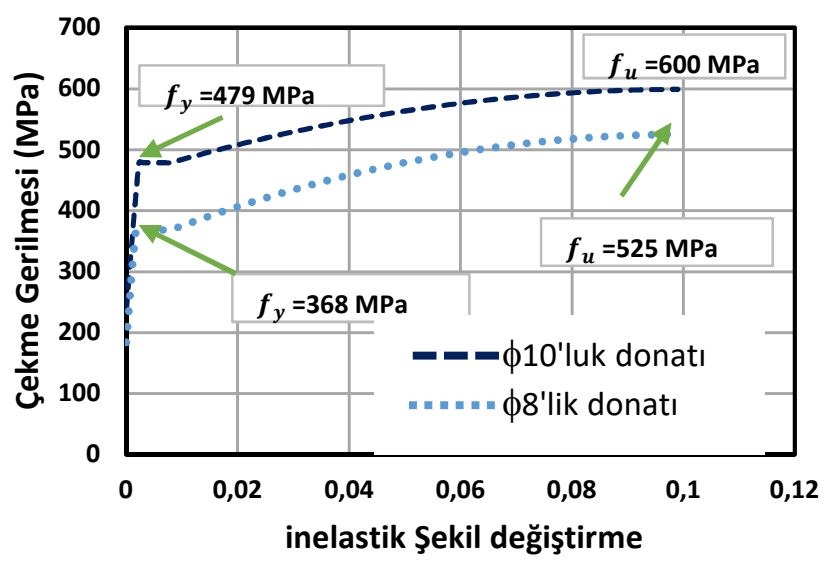

Şekil 6. Çelik donatı elasto-plastik davranış grafiği

\section{SEM Çalışma Sonuçları}

\subsection{Betonarme kiriş model doğrulama çalışmaları}

Üç boyutlu tasarımı ve malzeme modeli tamamlanan betonarme kirişlerin eğilme davranışı, model parametreleri girilerek modellenmiştir (Şekil 7). Betonarme kiriş modelinde Mander, Kent-Park ve Hognestad beton modelleri kullanılmıştır. Dilasyon açısı, çözüm ağı türü ve boyutu modelde değişken parametreler olarak kullanılmıştır. Dilsayon açısı 35-55 derece arasında, çözüm ağı türü hex ve hex-dominated ve boyutu 40-60 aralığında değişmektedir. Eksantirsitik: 0,05, fbo/fco: 1,16, K: 0,667 ve Visc. Parametresi: 0 sabit değişkenlerdir. Kullanılan üç modelde de, mesh-Hex ve mesh-hex-Dominated çözüm ağı türü, 50 mm çözüm ağı sık1lığ́ ve 40 dilasyon açısı deneye uygun sonucu verdiği ve çözüm ağları büyüdükçe kırılma dayanımının azaldığı gözlenmiştir. Ancak güçlendirilen kirişlerde en iyi sonuç Mander beton modeli, hex- dominated ve 50 ağ boyutu ile elde edilmiştir(Şekil 8).

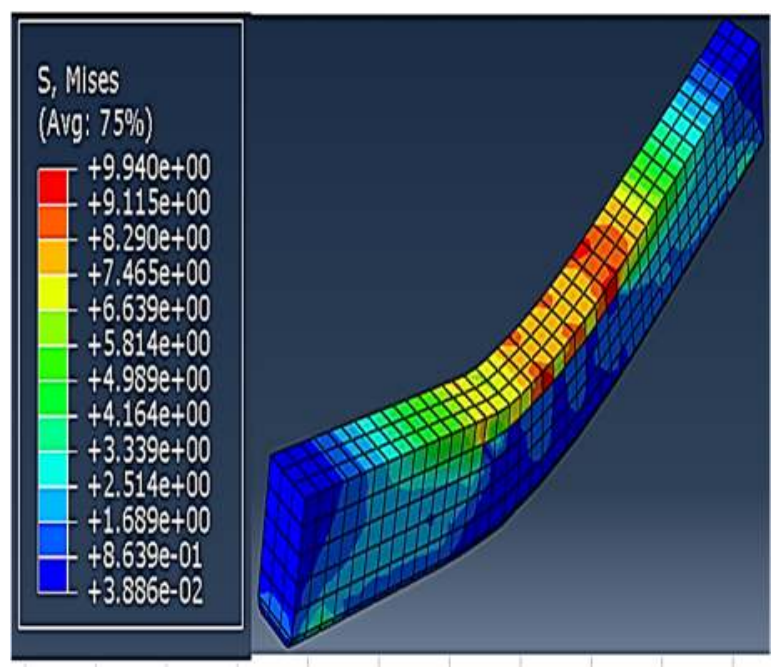

a) SEM beton gerilme dağılımları

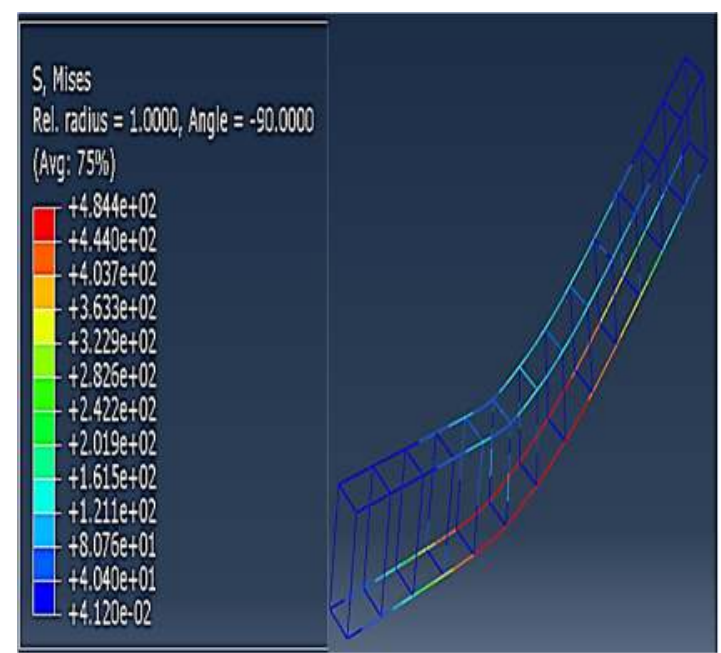

b) SEM donatı gerilme dağılımları

Şekil 7. SEM beton gerilme dağılımları(a), SEM donatı gerilme dağılımları(b) 


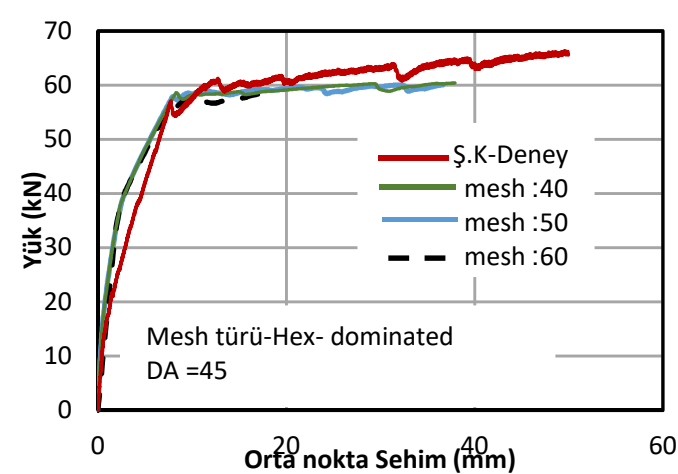

a) Mander modeli, mesh türü : hex-dominated, DA $=45$

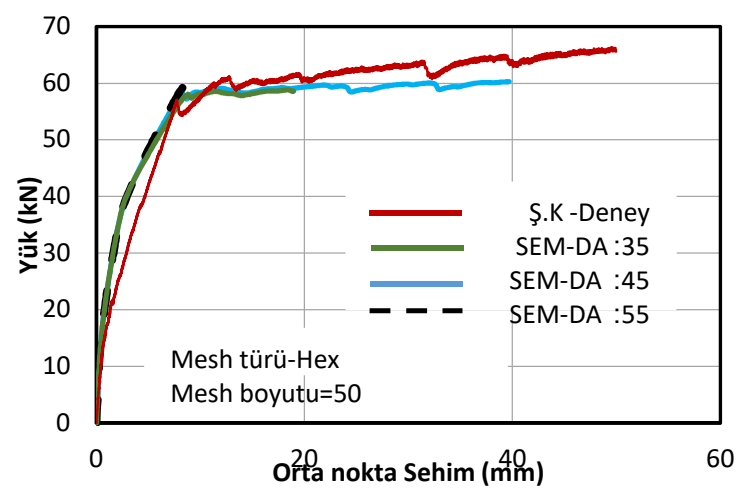

c) Mander modeli, mesh türü ve boyutu: hex, 50

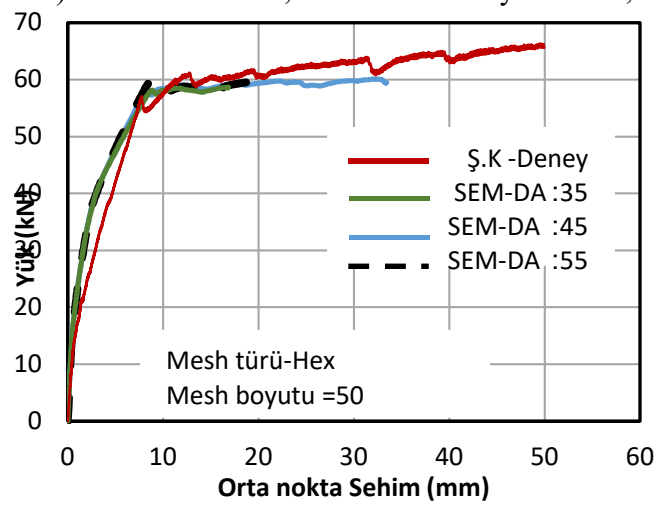

e) Kent -Park modeli, mesh türü ve boyutu: hex, 50

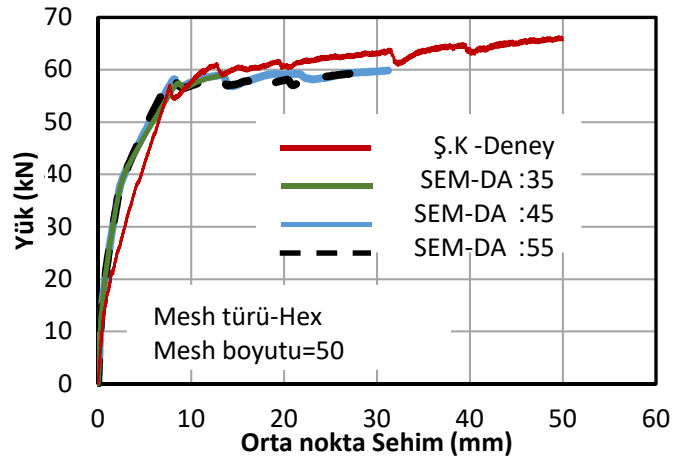

g) Hognestad modeli, mesh türü ve boyutu: hex, 50

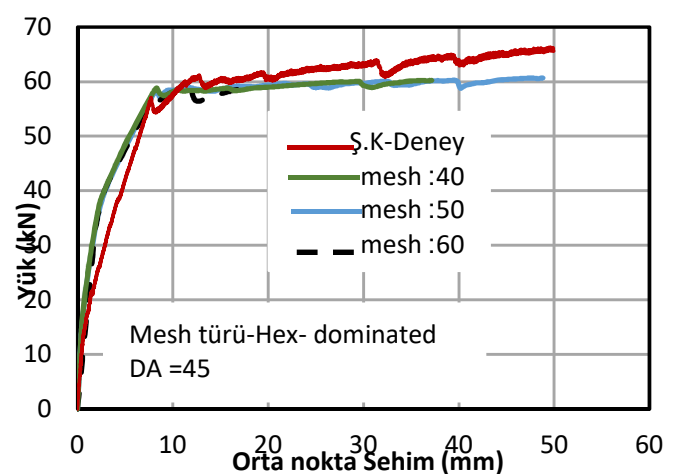

b) Kent-Park modeli, mesh türü : hex-dominated, DA $=45$

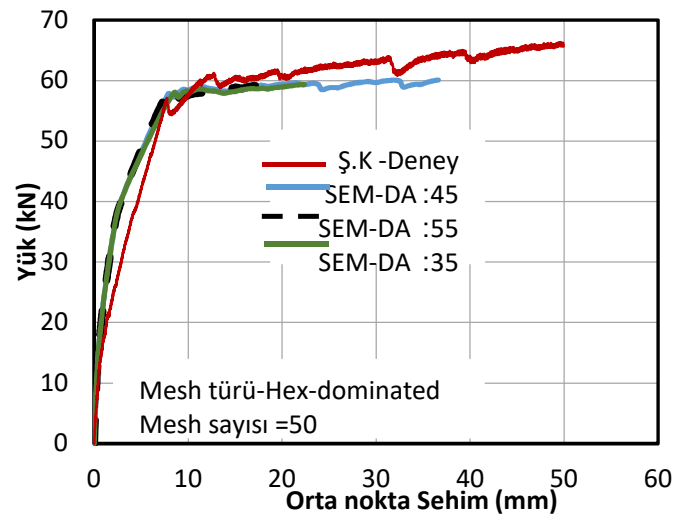

d) Mander modeli, mesh türü ve boyutu: Hex-dominated, 50

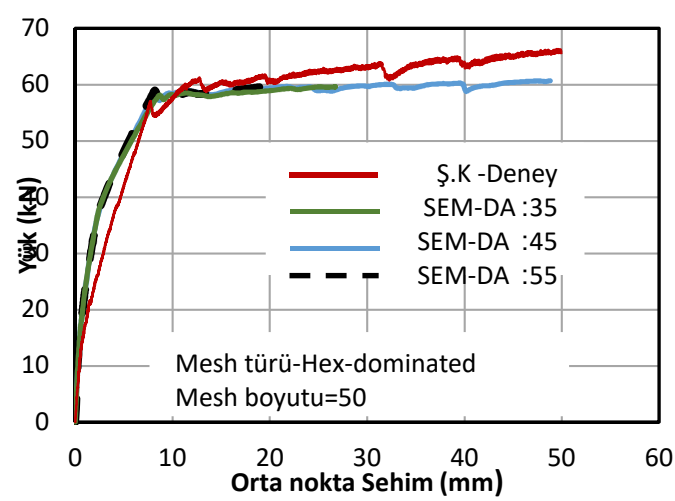

f) Kent-Park modeli, mesh türü ve boyutu: Hex-dominated, 50

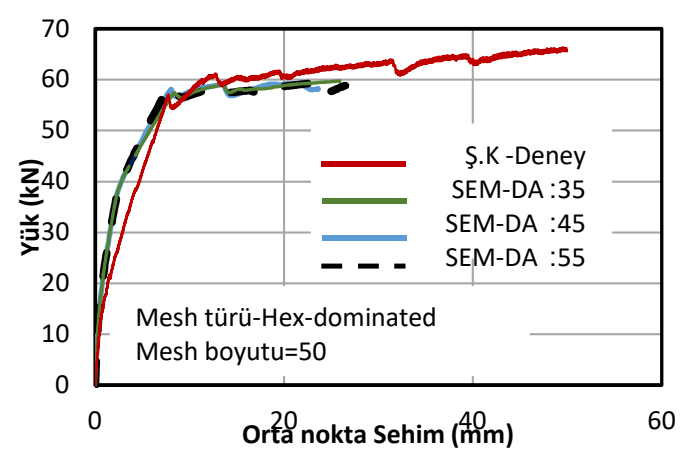

h) Hognestad modeli, mesh türü ve boyutu: Hex-dominat, 50

Şekil 8. Betonarme kontrol kirişi model doğrulama grafikleri 


\subsection{Güçlendirilen betonarme kiriş SEM analizi}

CFRP kompozitler ile güçlendirilmiş betonarme kirişler SEM programı ile analiz edilmiş ve

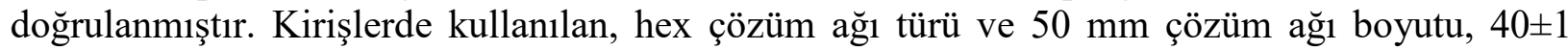
derece dilasyon açısı parametreleri deneysel çalışamaya yeterli yakınlıkta sonuçlar vermiştir. Güçlendirilen kirişlerin modeli incelendiğinde yenilme zarf eğrisi deney sonuçları ile uyumlu çıkmıştır. Kirişlerin kırılma yük ve sehim değerleri \%97 oranında yakalanmıştır. C21-1 kiriş modelinde SEM analizinde kiriş kırılma yüküne erişince deformasyon başlamış ve yük bir miktar daha artmıştır(Şekil 11). SEM analizinde de kiriş maksimum yüke eriştiğinde ani olarak göçmüştür(Şekil 9-11).

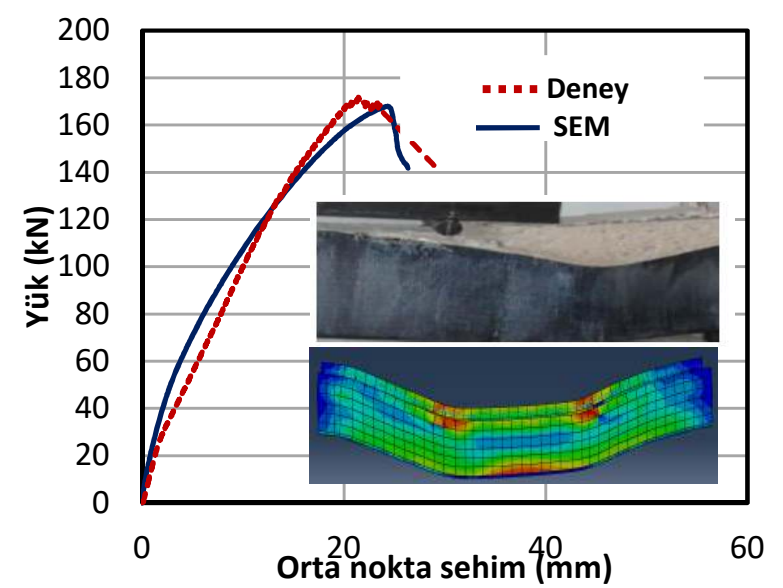

Şekil 9. C11 kirişi deney ve SEM analiz sonuçlarının karşılaştırılması

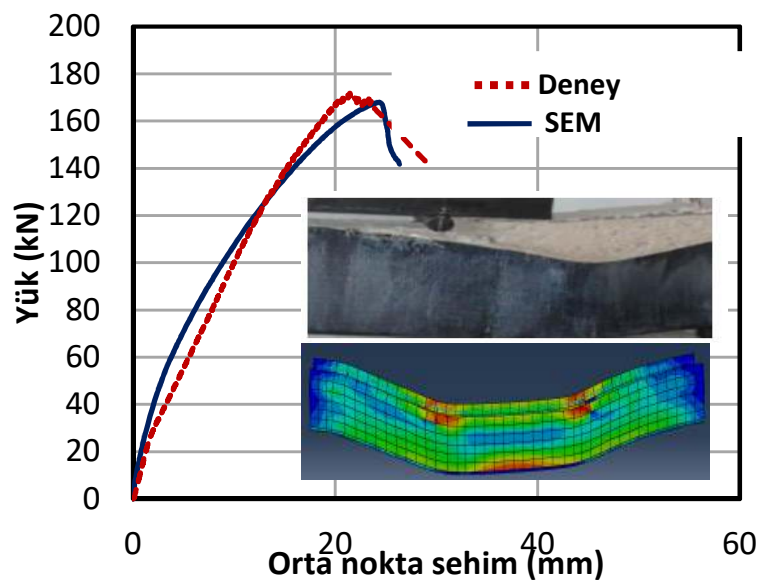

Şekil 10. C22 kirişi deney ve SEM analiz sonuçlarının karşılaştırılması

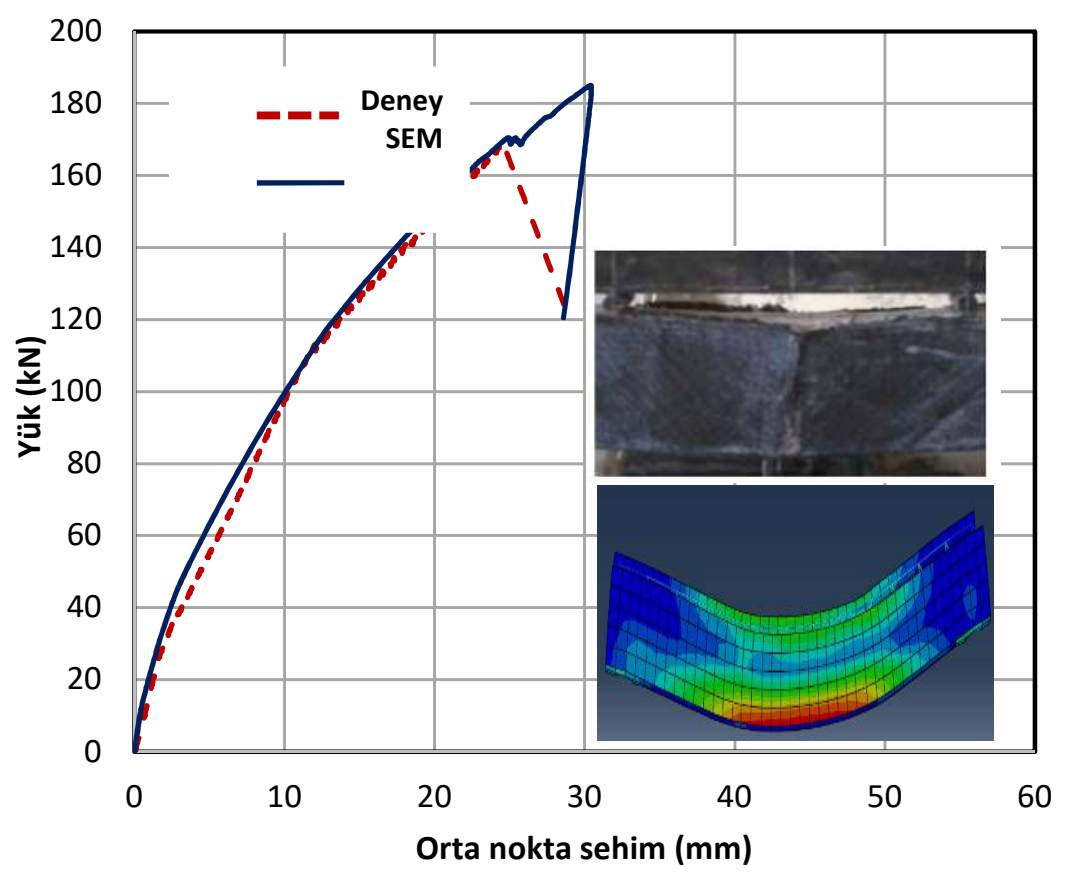

Şekil 11. C21-1 kirişi deney ve SEM analiz sonuçlarının karşılaştırılması 


\section{Sonuçlar ve Öneriler}

$\mathrm{Bu}$ çalışmada, düşük dayanımlı betonlar kullanılarak üretilen betonarme kirişler eğilme yüküne karşı CFRP kompozitler ile güçlendirilmiş ve Sonlu Elemanlar metodu (SEM) programı ile analiz edilmiştir. Deneysel çalışmadan elde edilen betonarme kiriş davranışları SEM ile modellenmiş ve doğrulanmıştır. CFRP kompozitler ile güçlendirilmiş kirişlerin deney sonuçları ve SEM analiz sonuçları karşılaştırılarak uygun parametreler tespit edilmiştir. Elde edilen sonuçlara göre;

- Kiriş davranışlarında deneysel çalışmaya en yakın sonuç Mander beton modeli ve 40 derece dilasyon açısı kullanılarak elde edilmiştir.

- FRP sargı katmanı artırıldığında kirişlerin yük taşıma kapasiteleri artmıştır. Ancak yük taşıma kapasitelerindeki artış CFRP sargı katmanındaki artışla aynı oranda olmadığı SEM ile de tespit edilmiştir.

- Kiriş dayanımı ve yenilme zarf eğrileri incelendiğinde SEM analiz sonuçları \%97 oranında deney sonuçları ile örtüşmüştür.

- SEM kullanılarak betonarme kirişlerin CFRP ile onarım ve güçlendirilmesinde daha hızlı, güvenilir ve ekonomik sonuçlar elde edilebilir. Ayrıca benzer özelliklere sahip kirişler deneysel çalışmaya gerek kalmadan farklı güçlendirme şekli, FRP türü ve oranı SEM ile analiz edilerek sayısal deney numuneleri üretilebilir.

\section{KAYNAKLAR}

[1] M. Saatcioglu et al., "The August 17, 1999, Kocaeli (Turkey) earthquake - damage to structures," Can. J. Civ. Eng., vol. 28, no. 4, pp. 715-737, 2001.

[2] A. Doğangün, "Performance of reinforced concrete buildings during the May 1, 2003 Bingöl Earthquake in Turkey," Eng. Struct., vol. 26, no. 6, pp. 841-856, 2004.

[3] E. Damci, R. Temur, G. Bekdaş, and B. Sayin, "Damages and causes on the structures during the October 23, 2011 Van earthquake in Turkey," Case Stud. Constr. Mater., vol. 3, pp. 112-131, 2015.

[4] H. Sezen, A. S. Whittaker, K. J. Elwood, and K. M. Mosalam, "Performance of reinforced concrete buildings during the August 17, 1999 Kocaeli, Turkey earthquake, and seismic design and construction practise in Turkey," Eng. Struct., vol. 25, no. 1, pp. 103-114, 2003.

[5] H. Kaplan, S. Yilmaz, H. Binici, E. Yazar, and N. Çetinkaya, "May 1, 2003 Turkey—Bingöl earthquake: damage in reinforced concrete structures," Eng. Fail. Anal., vol. 11, no. 3, pp. 279-291, 2004.

[6] M. Tapan, M. Comert, C. Demir, Y. Sayan, K. Orakcal, and A. Ilki, "Failures of structures during the October 23, 2011 Tabanli (Van) and November 9, 2011 Edremit (Van) earthquakes in Turkey," Eng. Fail. Anal., vol. 34, pp. 606-628, 2013.

[7] A. Bayraktar, A. C. Altunişik, and M. Pehlivan, "Performance and damages of reinforced concrete buildings during the October 23 and November 9, 2011 Van, Turkey, earthquakes," Soil Dyn. Earthq. Eng., vol. 53, pp. 49-72, 2013.

[8] M. C. Sundarraja and S. Rajamohan, "Strengthening of RC beams in shear using GFRP inclined strips - An experimental study," Constr. Build. Mater., vol. 23, no. 2, pp. 856-864, 2009.

[9] D.Preetam Prem Raj, "SHEAR AND FLEXURAL STRENGTHENING IN RC BEAMS USING FRP," Int. J. Sci. Technol. Manag., no. 4, pp. 8-16, 2015.

[10] M. R. Esfahani, M. R. Kianoush, and A. R. Tajari, "Flexural behaviour of reinforced 
concrete beams strengthened by CFRP sheets," Eng. Struct., vol. 29, no. 10, pp. 2428-2444, 2007.

[11] A. Saribiyik and N. Caglar, "Flexural strengthening of RC beams with low-strength concrete using GFRP and CFRP," Struct. Eng. Mech., vol. 58, no. 5, 2016.

[12] A. Saribiyik and N. Caglar, "Flexural strengthening of RC beams with low-strength concrete using GFRP and CFRP," Struct. Eng. Mech., vol. 58, no. 5, pp. 825-845, 2016.

[13] M. Aktas, Y. Sumer, E. Agcakoca, and Z. Yaman, "Nonlinear Finite Element Modeling of Composite Bridge Girders Strengthened with HM-CFRP Laminates," Arab. J. Sci. Eng., vol. 41, no. 10, pp. 3783-3791, 2016.

[14] N. Bulut, Ö. Anil, and Ç. M. Belgin, "Nonlinear finite element analysis of RC beams strengthened with CFRP strip against shear," Comput. Concr., vol. 8, no. 6, pp. 140-143, 2011.

[15] M. Naser, R. Hawileh, and H. Rasheed, "Modeling fire response of RC beams strengthened with CFRP laminates," in American Concrete Institute, ACI Special Publication, 2015, vol. 2015-Janua, no. SP 301, pp. 87-104.

[16] U. Khan, M. A. Al-Osta, and A. Ibrahim, "Modeling shear behavior of reinforced concrete beams strengthened with externally bonded CFRP sheets," Struct. Eng. Mech. An Int. J., vol. 61 , no. 1, pp. 127-144, 2017.

[17] M. Aktas and Y. Sumer, "Nonlinear finite element analysis of damaged and strengthened reinforced concrete beams," J. Civ. Eng. Manag., vol. 20, no. 2, pp. 201-210, 2014.

[18] A. Sarıbıyık, "Beton Dayanımı Düşük Betonarme Yapı Elemanlarının Lifli Kompozitler ile Güçlendirilmesi ve Karşılaştııılması," 2013.

[19] J. B. Mander, M. J. N. Priestley, and R. Park, "Theoretical Stress-Strain Model for Confined Concrete," J. Struct. Eng., vol. 114, no. 8, pp. 1804-1826, 1988.

[20] D. C. Kent and R. Park, "Flexural Members with Confined Concrete," in Journal of the Structural Division, 1971, vol. 97(ST7), pp. 1969-1990.

[21] E. Hognestad, "A Study of Combined Bending and Axial Load in Reinforced Concrete Members," Bull. Ser. No. 399, p. 128, 1951. 